\title{
ПРОБЛЕМЫ И ПЕРСПЕКТИВЫ ИННОВАЦИОННОГО ПРЕДПРИНИМАТЕЛЬСТВА В РОССИИ
}

\author{
(C) 2021 Удальцова Н.Л. \\ кандидат экономических наук, доцент департамента «Менеджмент» \\ Финансовый университет при Правительстве РФ, Россия, Москва \\ E-mail: NLUdaltsova@fa.ru
}

В статье приведены доводы в пользу целесообразности перехода российской экономики от консервативного к инновационному, социально ориентированному шаблону развития. Представлена краткая характеристика общей инновационной деятельности в российском предпринимательстве. Сформулирован ряд проблем, тормозящих развитие бизнеса в стране и препятствующих рациональному использованию ресурсов. Рассмотрены наиболее известные инновационные компании России, активно работающие с интеллектуальной собственностью и открытыми инновациями.

Ключевые слова: предпринимательство, инновации, технологии

\section{Введение}

В условиях глобализации, интенсивного экономического развития предприятий, увеличения роли инновационных технологий в предпринимательской деятельности и других процессов, происходящих в передовых технологических странах по всему миру, условиях игры для предпринимателей в России постепенно меняются. Чтобы иметь возможность производить конкурентоспособные товары, востребованные на рынке, малому, среднему и крупному бизнесу в России приходится развивать инновационные технологии, так как это единственный эффективный способ повышения конкурентоспособности с опорой на быстро меняющуюся рыночную экономику.

Актуальность выбранной темы объясняется современным пониманием инновационного предпринимательства как важнейшего компонента повышения конкурентоспособности страны.

\section{Основная часть}

Согласно данным научно-технологического комплекса ФГБНУ НИИ РИНКЦЭ, в 2019 году на территории Российской Федерации действовала 4051 организация, выполняющая научные исследования и разработки, связанные с интеллектуальной собственностью (Таблица 1). Наибольше количество инновационных компаний сосредоточено в Центральном (36,2\%), Приволжском (17\%) и Северо-Западном $(12,8 \%)$ федеральных округах. Одновременно с этим в стране осуществляло свою деятельность 9839 инновационных компаний, из которых также большинство были локализовано в Центральном $(33,4 \%)$, Приволжском $(22,4 \%)$ и Северо-Западном (12\%) федеральных округах. На основе этого можно заключить, что треть всех инновационных организаций сосредоточена в Центральной части России, при этом удельный вес компаний, осуществляющих инновационную деятельность, в общем числе обследованных организаций,

Таблица 1. Уровень инновационной активности организаций по федеральным округам РФ за 2019 г.

\begin{tabular}{|l|l|}
\hline \multicolumn{1}{|c|}{ Территория } & \multicolumn{1}{c|}{$\begin{array}{c}\text { Уровень инновационной активности } \\
\text { организаций, \% }\end{array}$} \\
\hline Российская Федерация & 9,1 \\
\hline Приволжский & 11,6 \\
\hline Центральный & 10,8 \\
\hline Северо-Западный & 10,1 \\
\hline Уральский & 9,3 \\
\hline Южный & 7,5 \\
\hline Сибирский & 7,5 \\
\hline Дальневосточный & 6,0 \\
\hline Северо-Кавказский & 1,7 \\
\hline
\end{tabular}


иными словами уровень инновационной активности предприятий в регионе, распределяется по стране иначе (Таблица 1).

Список наиболее известных инновационных компаний выглядит следующим образом [составлено автором]:

1. Банк Сбер;

2. Яндекс;

3. Норникель;

4. Mail.ru Group;

5. X5 Retail;

6. Ростех;

7. Вымпелком;

8. Росатом;

9. MTC.

Основной проблемой был и остаётся недостаток финансирования. Банкам гораздо проще зарабатывать деньги на операциях, не связанных с производственным процессом, из-за чего они крайне редко включаются в игру на начальной стадии развития инновационной компании. Кредиты и займы компенсируют порядка 15\% затрат на технологии (Рисунок 1). Государство также предпочитает не вмешиваться в технологическую деятельность компаний: совокупная федеральная и региональная финансовая поддержка покрывает примерно одну десятую часть расходов на инновации (9\% - за счёт федерального бюджета, 0,3\% - за счёт бюджета субъектов России и местных бюджетов). Таким образом, выходит, что инновационная деятельность предприятий осуществляется преимущественно за счёт собственных средств. Особенно ярко это проявляется при добыче угля, производстве табака и кожаных изделий, где доля собственных средств достигает 100\%. В других сферах производства этот показатель держится на уровне 70\% $[1$, с. 1$]$.

Всё это характеризуется взаимным недоверием государства и кредитных организаций с одной стороны и бизнеса - с другой, что приводит к внутреннему сдерживанию экономического роста и, следовательно, отсутствию интереса зарубежных процессов к финансированию российских организаций.

Ещё одна не менее важная проблема - неразвитость банковской системы, выражающаяся в высоких процентных ставках и относительно небольших суммах. Организациям не выдаются просто бюджетные деньги, вместо них предлагаются кредиты. Но далеко не все даже работающие предприятия способны позволить себе взять кредит и возвратить его в соответствии с законодательством РФ. Из-за этого становится привычной ситуация, в которой рискованность кредитов в государственных банках и облигаций в небанковских учреждениях выходит на один уровень. Скоринговые алгоритмы и риск-менеджмент банков ставят вынуждают заёмщиков обращаться в различные микрофинансовые организации или к ссудам теневой экономики.

Одновременно с этим проблемой становятся и основные и оборотные фонды. Поскольку российский рынок относится к рынку развивающейся экономики, лишь небольшая часть малых и средних фирм может позволить себе выход на IPO для привлечения дополнительного финансирования. Из-за неразвитости слияний и поглощений (Mergers \& Acquisitions) мелкие компании редко поглощаются крупными, не имея возможности выйти на международный рынок
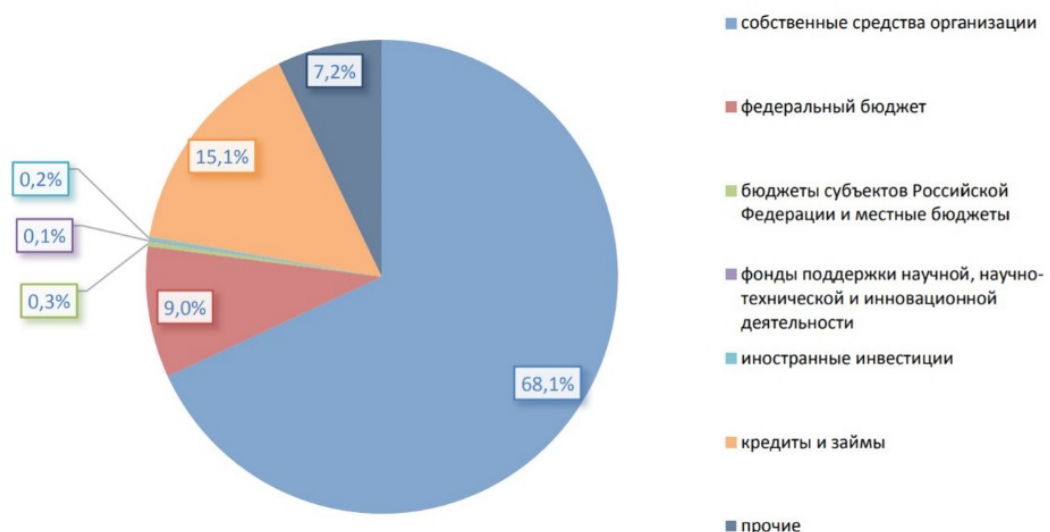

Puc. 1. Структура затрат на технологические инновации организаций промышленного производства по источникам финансирования в 2017 (\%) [1, с. 1]. 
и зря растрачивая свой потенциал. Кроме того, высокие налоги приводят к тому, что предприятия отдают предпочтение арендованным фондам, увеличивая разницу между объёмами реализации и взятыми фондами, отпугивая, таким образом, потенциальных иностранных инвесторов [2, с. 25].

Из всего этого вытекает ещё одна проблема: низкий инновационный климат и повышенные риски в сфере предпринимательства. Организовывая новую инновационную структуру, предприниматель всегда понимает, что, в случае недостатка финансирования или отсутствия спроса, ему будет неоткуда взять необходимые ресурсы, и предприятие придётся закрыть. Кроме того, риски в российской инновационной активности можно объяснить отсутствием точности в понимании сроков окупаемости, а также значительным отставанием России в сфере финансовой поддержки предпринимательства по сравнению с развитыми странами. К внутренним рискам, способным развалить успешную компанию из- нутри, относятся слабая кооперация сотрудников компании и недостаточная крепость связей между руководящими должностями [3, с. 71-72]. Это приводит к тому, что удельный вес инновационных организаций по отношению ко всем организациям составляет всего 9,2\%, а удельный вес технологически усовершенствованных товаров $-8,4 \%$ (Таблица 2 ).

Что касается патентной активности, тут основная сложность связана с новизной правового поля и неустоявшимися традициями относительно патентов в юридической деятельности российских предпринимателей. Осознание патентной системы как самостоятельной отрасли экономики и права началось меньше 30-и лет назад, а официальное закрепление норм, касающихся этой области, произошло только в 2006 г. (гл. 72 ГК РФ). Патентная активность в России остаётся неизменной на протяжении последних 10 лет (Таблица 3), в то время как в Китае, например, число патентов за этот период возросло почти в 3 раза [WIPO statistics database].

Таблица 2. Рейтинг стран по числу инновационных компаний на 2018 г. [4, с. 1].

\begin{tabular}{|c|c|c|c|c|c|c|c|c|c|c|}
\hline \multirow[t]{2}{*}{ Страна } & \multicolumn{2}{|c|}{$\begin{array}{c}\text { Удельный вес } \\
\text { организаций, } \\
\text { осуществлявших } \\
\text { технологические } \\
\text { инновации, в } \\
\text { общем числе } \\
\text { организаций }\end{array}$} & \multicolumn{2}{|c|}{$\begin{array}{c}\text { Удельный вес } \\
\text { инновационных } \\
\text { товаров, работ, } \\
\text { услуг в общем } \\
\text { объеме отгру- } \\
\text { женных товаров, } \\
\text { выполненных } \\
\text { работ, услуг }\end{array}$} & \multicolumn{2}{|c|}{$\begin{array}{c}\text { Удельный вес } \\
\text { затрат на техно- } \\
\text { логические инно- } \\
\text { вации в общем } \\
\text { объеме отгружен- } \\
\text { ных товаров, вы- } \\
\text { полненных работ, } \\
\text { услуг }\end{array}$} & \multicolumn{2}{|c|}{$\begin{array}{c}\text { Удельный вес } \\
\text { затрат на ис- } \\
\text { следования и } \\
\text { разработки в } \\
\text { общем объеме } \\
\text { затрат на тех- } \\
\text { нологические } \\
\text { инновации }\end{array}$} & \multicolumn{2}{|c|}{$\begin{array}{c}\text { Удельный вес орга- } \\
\text { низаций, участвую- } \\
\text { щих в совместных } \\
\text { проектах по выпол- } \\
\text { нению исследований } \\
\text { и разработок, в об- } \\
\text { щем числе организа- } \\
\text { ций, осуществлявших } \\
\text { технологические ин- } \\
\text { новации }\end{array}$} \\
\hline & $\begin{array}{c}\text { позиция } \\
\text { страны }\end{array}$ & $\%$ & $\begin{array}{c}\text { позиция } \\
\text { страны }\end{array}$ & $\%$ & $\begin{array}{c}\text { позиция } \\
\text { страны }\end{array}$ & $\%$ & $\begin{array}{c}\text { позиция } \\
\text { страны }\end{array}$ & $\%$ & $\begin{array}{c}\text { позиция } \\
\text { страны }\end{array}$ & $\%$ \\
\hline Россия & 28 & 9.2 & 28 & 8.4 & 20 & 1.8 & 22 & 23.6 & 22 & 28.6 \\
\hline Бельгия & 1 & 59.7 & 23 & 11.8 & 11 & 2.7 & 8 & 69.1 & 1 & 61.2 \\
\hline Германия & 2 & 58.9 & 11 & 19.4 & 2 & 4.7 & 9 & 61.3 & 24 & 25.0 \\
\hline Ирландия & 3 & 56.8 & 12 & 19.0 & 29 & $\ldots$ & 28 & $\ldots$ & 14 & 34.0 \\
\hline Нидерланды & 4 & 53.0 & 14 & 17.4 & 12 & 2.7 & 29 & $\ldots$ & 7 & 42.7 \\
\hline Австрия & 5 & 52.5 & 13 & 18.5 & 7 & 3.0 & 5 & 77.1 & 4 & 50.2 \\
\hline Финляндия & 6 & 52.0 & 16 & 15.2 & 3 & 3.7 & 2 & 86.4 & 9 & 40.6 \\
\hline Швеция & 7 & 48.0 & 26 & 9.7 & 1 & 7.6 & 7 & 70.5 & 15 & 34.0 \\
\hline Франция & 8 & 46.5 & 4 & 23.6 & 5 & 3.5 & 4 & 79.4 & 12 & 35.5 \\
\hline Великобритания & 9 & 45.7 & 1 & 43.5 & 15 & 2.2 & 14 & 39.1 & 2 & 58.2 \\
\hline Португалия & 10 & 45.4 & 29 & 7.9 & 23 & 1.6 & 15 & 36.5 & 27 & 18.3 \\
\hline
\end{tabular}

Таблица 3 Динамика и структура патентных заявок в РФ [5].

\begin{tabular}{|l|c|c|c|c|c|c|c|c|c|c|}
\hline \multicolumn{1}{|c|}{ Вид ОПС } & $\mathbf{2 0 0 9}$ & $\mathbf{2 0 1 0}$ & $\mathbf{2 0 1 1}$ & $\mathbf{2 0 1 2}$ & $\mathbf{2 0 1 3}$ & $\mathbf{2 0 1 4}$ & $\mathbf{2 0 1 5}$ & $\mathbf{2 0 1 6}$ & $\mathbf{2 0 1 7}$ & $\mathbf{2 0 1 8}$ \\
\hline Изобретения & 38564 & 42500 & 41414 & 44211 & 44914 & 40308 & 45517 & 41587 & 36454 & 37957 \\
\hline Полезные модели & 11153 & 12262 & 13241 & 14069 & 14358 & 13952 & 11906 & 11112 & 10643 & 9747 \\
\hline $\begin{array}{l}\text { Промышленные } \\
\text { образцы }\end{array}$ & 3740 & 3997 & 4197 & 4640 & 4994 & 5184 & 4929 & 5464 & 6487 & 5908 \\
\hline Товарные знаки & 50107 & 56848 & 59717 & 61923 & 64928 & 61188 & 61477 & 64762 & 73510 & 76062 \\
\hline \multicolumn{1}{|c|}{ Всего } & $\mathbf{1 0 3 5 6 4}$ & $\mathbf{1 1 5 6 0 7}$ & $\mathbf{1 1 8 5 6 9}$ & $\mathbf{1 2 4 8 4 3}$ & $\mathbf{1 2 9 1 9 4}$ & $\mathbf{1 2 0 6 3 2}$ & $\mathbf{1 2 3 8 2 9}$ & $\mathbf{1 2 2 9 2 5}$ & $\mathbf{1 2 7 0 9 4}$ & $\mathbf{1 2 9 6 7 4}$ \\
\hline
\end{tabular}


Кроме локальной патентной проблемы, важную роль играет и общая несогласованность в законодательной и налоговой базе РФ, которая приводит к путанице и неразберихе в федеральных и локальных законах, касающихся высокотехнологичной инновационной деятельности. Ключевые термины - «инновация» и «инновационная деятельность» - встречаются только в 2-х федеральных законах РФ: Ф3 № 127 от 23.08.1996 г. («О науке и государственной научно-технической политике») и ФЗ № 216 от 29.07.2017 г. («Об инновационных научно-технологических центрах и о внесении изменений в отдельные законодательные акты РФ»). В это же время Департамент стратегического развития и инноваций своими основными документами называет Указ Президента России от 7 мая 2018 года № 204 «О национальных целях и стратегических задачах развития России на период до 2024 года», который не содержит в себе ни расшифровки термина «инновация», ни определения статуса технопарков как ведущего инструмента интеграции науки и промышленности, ни других ключевых понятий в сфере высокотехнологичного производства.

На настоящий момент направление для развития ведущих развитых стран формируется на основе глобализации мировой экономики, инфляции, роста конкуренции и увеличения ценности ресурсов электроэнергетики [2, с. 29]. Поскольку главными стимулами для внедрения инноваций в таких условиях являются сокращение издержек производства и увеличение конкурентоспособности, российской экономике следует ориентироваться именно на эти факторы развития. Россия находится на экономическом и политическом перепутье, и от выбора направления зависит дальнейшая судьба государства. В общем, для решения проблемы инновационного российского предпринимательства, необходимо следующее.

1. Наращение человеческого потенциала в областях науки, экономики и политики путём открытия инновационно-технологических центров и технопарков при ВУЗах, создания эффективной системы стимулов для высококвалифицированного персонала, повышения восприимчивости к новым технологиям и отказа от консервативной политики.
2. Разработка новых венчурных программ финансирования, независимых от неустоявшегося российского законодательства и экономического влияния зарубежных государств. Оптимальным решением может быть предоставление инновационным компаниям энергетических и других ресурсов на льготных условиях, а также ввод таможенных и налоговых льгот для этой категории юрлиц.

3. Повышение уровня инновационности самого государства, а также адаптация российского законодательства к современным экономическим и научным реалиям, требующим узаконенной нормативно-правовой базы, включающей в себя определение терминов «инновация» и «инновационная активность». Параллельно с этим должны быть запущены процессы информатизации и диджитализации.

4. Формирование сбалансированного и стабильного научного сектора научных исследований на базе НИОКР, его поддержка государством и ведущими инновационными компаниями, коммерциализация новейших разработок.

5. Повышение открытости национальной инновационной системы РФ: усиление интеграции России в различные системы многостороннего инновационного сотрудничества и организация выставок и презентаций продуктов в регионах.

\section{Заключение}

В заключение необходимо добавить, что ещё 20 лет назад инновационная политика России характеризовалась отсутствием чётко выраженной концепции, которая ориентировалась бы на создание функциональной высокотехнологической системы, интегрированной в политическое, научное и экономическое пространство зарубежных развитых стран. Россия нуждается в новой экономической политике, которая бы включала в себя отказ от консервативной модели «закрытых инноваций» и предполагала бы активную интеграцию России в международные инновационные процессы. При этом для успешного проведения реформ в области высокотехнологичной деятельности инициатива должна идти сверху, от государства. В противном случае предпринимательство в России не сможет удержаться на текущем мировом уровне, и международные экономические показатели России упадут. 


\section{Библиографический список}

1. Е.И.Лукинова; К.А.Дитковский. (2019). Наука и Инновации. URL: https://issek.hse.ru/ data/2019/02/13/1206653030/NTI_N_119_13022019.pdf.

2. К.А.Осока (2018). Инновационное предпринимательство. URL: https://kubsu.ru/sites/default/files/ users/21445/portfolio/innovacionnoe_predprinimatelstvo_kursovaya_rabota_osoka_k.a.pdf.

3. А. А. Никонова. (2015). Системность управления как основной императив в переходе к устойчивому развитию. Эффективное антикризисное управление.

4. С. Ю.Фридлянова; Е.И.Лукинова. (2018). Наука и Инновации. URL: https://issek.hse.ru/mirror/pubs/ share/221937467.

5. Федеральная служба государственной статистики. [Электронный ресурс]. URL: https://rospatent.gov.ru/ru/ about/stat.

6. Knoema Enterprise. [Электронный ресурс]. URL: https://knoema.ru/GII2018Aug/global-innovation-index-2020.

7. World Economic Forum. [Электронный ресурс]. URL: https:/gtmarket.ru/ratings/global-competitiveness-index.

8. EBRD. [Электронный ресурс]. URL: https://www.ebrd.com/news/publications/brochures/ebrd-knowledgeeconomy-index.html. 